\title{
Engineering selectivity for reduced toxicity of bacterial kinase inhibitors using structure-guided medicinal chemistry
}

Nathan Wlodarchak, ${ }^{1,2}$ John B. Feltenberger, ${ }^{3}$ Zhengqing Ye, ${ }^{3}$ Jeffrey Beczkiewicz, ${ }^{2}$ Rebecca Procknow, ${ }^{2}$ Gang Yan, ${ }^{4}$, Troy M. King Jr. ${ }^{2}$, Jennifer E. Golden, ${ }^{3,4}$ Rob Striker ${ }^{1,2 *}$

${ }^{1}$ William S. Middleton Veterans Hospital, 2500 Overlook Terrace, Madison, WI $53705{ }^{2}$ University of Wisconsin-Madison Department of Medicine, 1550 Linden Dr, Madison, WI 53706, ${ }^{3}$ University of Wisconsin-Madison Medicinal Chemistry Center, School of Pharmacy, University of WisconsinMadison, 777 Highland Avenue, Madison, WI 53705 'Division of Pharmaceutical Sciences, School of Pharmacy, University of Wisconsin-Madison, 777 Highland Avenue, Madison, WI 53705

\section{Table of Contents}

I. Methods
A. Protein Purification
B. Screening
C. Design and docking
D. Synthesis

i. General method A

ii. General method B

E. Biochemical activity \& affinity assays

F. Physical property assays

G. Bacterial assays

H. Cellular toxicity testing

I. Zebrafish toxicity testing

II. Figure S1

III. Supplemental References

IV. Table S1 (separate file in .xlsx format)

V. Table S2 (separate file in .xlsx format)

VI. NMR Chromatograms (separate file in .pdf format)

\section{I. $\quad$ Methods}

A. Protein purification: $\mathrm{PknB}$ and GarA were purified as described previously ${ }^{1}$. Constructs for Cdk2 and Cyclin A were obtained from the Xing lab from the author's previous work and purified similarly ${ }^{2}$. Bacteria containing either $\mathrm{Cdk} 2$ or Cyclin A construct was grown to log phase at $37^{\circ} \mathrm{C}$ and induced with $1 \mathrm{mM}$ IPTG overnight at $23^{\circ} \mathrm{C}$. Harvesting, lysis, affinity purification, and separation of free GST from Cdk2 or Cyclin A was performed exactly as for PknB. Purified Cdk2 and Cyclin A were combined at a 1:1 molar ratio and allowed to sit at $4{ }^{\circ} \mathrm{C}$ for one hour. The mixture was injected onto a Superdex 75 column (GE) for size exclusion purification using a buffer containing $20 \mathrm{mM}$ Tris pH 8.0, $1 \mathrm{mM}$ DTT, $1 \mathrm{mM} \mathrm{MgCl}$, and $150 \mathrm{mM}$ $\mathrm{NaCl}$. The peaks were assessed by size and SDS_PAGE and the peak corresponding to a Cdk2-Cyclin A dimer was collected and the protein was flash frozen and stored at $-80^{\circ} \mathrm{C}$. Myelin basic protein was obtained from Sigma. 
B. Screening: The computational screen from our previous work and a machine learning prediction confirmed by a biochemical screen of the PKIS I and II libraries from a collaboration both suggested $\mathbf{1}$ as an active PknB inhibitor ${ }^{1,3}$. We obtained 1 commercially (AKSci) and 30 structurally related aminopyrimidines from David Drewry at UNC4. We utilized the Small Molecule Facility at UW-Madison to plate these compounds using a 10-point 2-fold serial dilution from 20 to $0.005 \mu \mathrm{M}$ and conducted a biochemical assay to determine PknB inhibition following the same procedures as the PKIS screen.

C. Design and docking: Novel compounds were designed and rendered in ChemDraw Pro (Perkin Elmer) and SMILES were exported and converted to 3D structures and docked in PknB (1O6Y), ${ }^{5}$ PnA (6B2Q), PknE (2H34), ${ }^{7}$ PknG (2PZI), ${ }^{8}$ PknI (5XKA), ${ }^{9}$ Cdk2-Cyclin A (1FIN), ${ }^{10}$ and Cdk4-Cyclin D3 (3G33) ${ }^{11}$ following published procedures ${ }^{1}$. A model of $\mathrm{PknD}$ was determined using the iTasser server ${ }^{12}$ using $\mathrm{PknB}$ $(1 \mathrm{O} 6 \mathrm{Y})$ as a template and docking was carried out as described above.

D. Synthesis: All reactants and reagents were ACS reagent grade or better, and were purchased from SigmaAldrich, Combi-Blocks, Ark Pharm, Matrix Scientific, Alfa Aesar, Enamine, Astatech, or Oakwood Chemical, and used without further purification. GW779439X was purchased from AKScientific and was $>95 \%$ purity. Vinylogous amides were commercially available or known and synthesized according to literature procedure. All reactions in non-aqueous media were conducted under a positive pressure of dry argon in glassware that had been dried in oven prior to use unless noted otherwise. All solvents were dried prior to use unless noted otherwise. Thin layer chromatography was performed using precoated silica gel plates (EMD Chemical Inc. 60, F254). Microwave reactions were performed on an Anton Paar Monowave 300 system in G10 vials. Flash column chromatography was performed with silica gel (RediSep Rf Gold, 20-40 $\mu \mathrm{m}$ ) on a Teledyne Isco CombiFlash system. Prep-HPLC chromatography was performed on a Teledyne Isco RediSep Prep C18 column $(5 \mu \mathrm{m}, 100 \AA$, $20 \times 150 \mathrm{~mm})$ on a Teledyne Isco EZ-Prep system. ${ }^{1} \mathrm{H}$ nuclear magnetic resonance spectra (NMR) were obtained on a Bruker $400 \mathrm{MHz}$ or Varian Unity-Inova $500 \mathrm{MHz}$ recorded in ppm $(\delta)$ downfield of TMS $(\delta=0)$ in $\mathrm{CDCl} 3$, Methanol- $d_{4}$, unless noted otherwise. Signal splitting patterns were described as singlet (s), doublet (d), triplet (t), quartet (q), quintet (quint), or multiplet (m), with coupling constants $(\mathrm{J})$ in hertz. The liquid chromatography mass spectrometry LC-MS analysis of final products was processed on Agilent 1290 Infinity II LC system using Poroshell 120 EC-C18 column $(5 \mathrm{~cm} \times 2.1 \mathrm{~mm}, 1.9$ $\mu \mathrm{m})$ for chromatographic separation. Agilent 6120 Quadrupole LC/MS with multimode Electrospray Ionization plus atmospheric pressure chemical ionization (MM-ES+APCI) was used for detection. The mobile phases were 5.0\% methanol and $0.1 \%$ formic acid in purified water (A) and $0.1 \%$ formic acid in methanol (B). The gradient was held at 5\% (0-0.2 min), increased to $100 \%$ at $2.5 \mathrm{~min}$, then held at isocratic $100 \%$ B for 0.4 min and then immediately stepped back down to $5 \%$ for 0.1 min re-equilibration. The flow rate was set at $0.8 \mathrm{~mL} / \mathrm{min}$. Column temperature was set at $40{ }^{\circ} \mathrm{C}$. The purities of all the final compounds were determined to be over 95\% by LCMS. HRMS was determined on Bruker MaXis Ultra-High Resolution Quadrupole Time-of-Flight MS, ESI infusion, positive ion mode.

\section{i. General method A:}
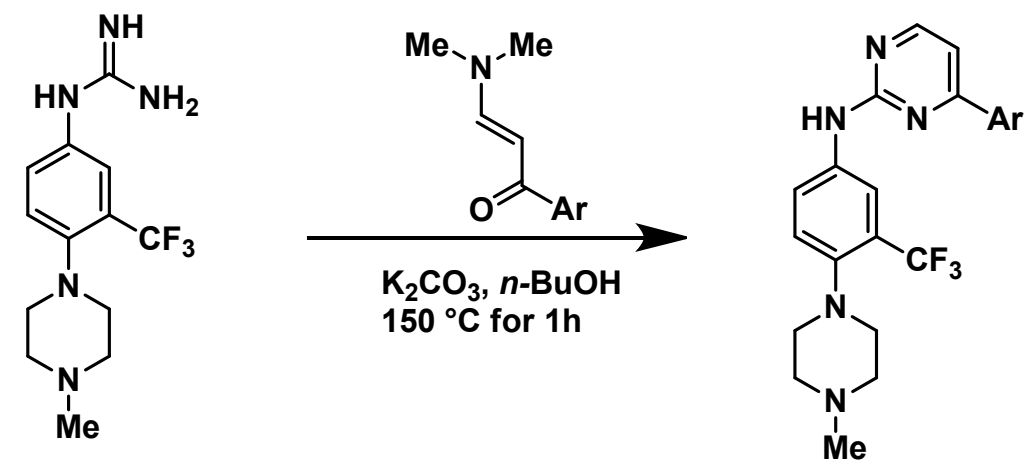
General method A: To a solution of (2E)-3-(dimethylamino)-1-(aryl-3-yl)prop-2-en-1-one (0.2 mmol) and $N$-[4-(4-methylpiperazin-1-yl)-3-(trifluoromethyl)phenyl]guanidine (0.24 mmol, 1.2 equiv) in $n$-butanol (2 $\mathrm{mL}$ ) was added $\mathrm{K}_{2} \mathrm{CO}_{3}\left(0.6 \mathrm{mmol}, 3\right.$ equiv.) and stirred at $150{ }^{\circ} \mathrm{C}(\mathrm{MW})$ for $1 \mathrm{~h}$. The mixture was purified by reverse phase Prep-HPLC column with water $(0.1 \%$ formic acid $) /$ acetonitrile $(0.1 \%$ formic acid $)$ gradient.

\section{ii. General method B:}
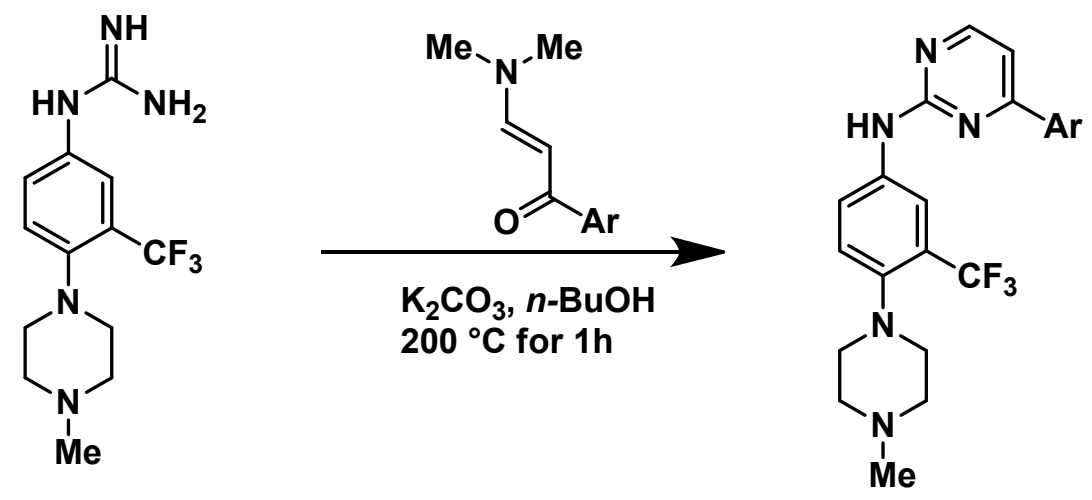

General method B: To a solution of (2E)-3-(dimethylamino)-1-(aryl-3-yl)prop-2-en-1-one (0.4 mmol) and $N$-[4-(4-methylpiperazin-1-yl)-3-(trifluoromethyl)phenyl]guanidine (0.48 mmol, 1.2 equiv) in $n$-butanol (5 $\mathrm{mL}$ ) was added $\mathrm{K}_{2} \mathrm{CO}_{3}\left(2 \mathrm{mmol}, 5\right.$ equiv.) and stirred at $200{ }^{\circ} \mathrm{C}(\mathrm{MW})$ for $1 \mathrm{~h}$. The mixture was purified by reverse phase Prep-HPLC column with water $(0.1 \%$ formic acid)/acetonitrile $(0.1 \%$ formic acid) gradient or flash column.<smiles>CN1CCN(c2ccc(Nc3nccc(-c4cccnc4)n3)cc2C(F)(F)F)CC1</smiles>

N-(4-(4-methylpiperazin-1-yl)-3-(trifluoromethyl)phenyl)-4-(pyridin-3-yl)pyrimidin-2-amine

General method A, using commercially available (E)-3-(Dimethylamino)-1-(pyridin-3-yl)prop-2-en-1-one. Isolated as a $2 \mathrm{x}$ formate salt. 54\% yield. ${ }^{1} \mathrm{H}$ NMR $(500 \mathrm{MHz}$, Chloroform- $d$ ) $\delta 9.25$ (d, J = 2.3 Hz, $1 \mathrm{H}), 8.72$ $(\mathrm{dd}, \mathrm{J}=4.8,1.7 \mathrm{~Hz}, 1 \mathrm{H}), 8.49(\mathrm{~d}, \mathrm{~J}=5.1 \mathrm{~Hz}, 1 \mathrm{H}), 8.40-8.37(\mathrm{~m}, 1 \mathrm{H}), 8.33(\mathrm{~s}, 1 \mathrm{H}), 8.22(\mathrm{~d}, \mathrm{~J}=2.7 \mathrm{~Hz}, 1 \mathrm{H})$, $7.78(\mathrm{dd}, \mathrm{J}=8.6,2.6 \mathrm{~Hz}, 1 \mathrm{H}), 7.47(\mathrm{dd}, \mathrm{J}=8.0,4.8 \mathrm{~Hz}, 1 \mathrm{H}), 7.41(\mathrm{~d}, \mathrm{~J}=8.6 \mathrm{~Hz}, 1 \mathrm{H}), 7.23(\mathrm{~d}, \mathrm{~J}=5.2 \mathrm{~Hz}$, 1H), 3.17 (s, 8H), 2.75 (s, 3H). ${ }^{13} \mathrm{C}$ NMR (125 MHz, Chloroform-d) $\delta 162.7,159.9,158.9,151.4,148.2,144.4$, 137.8, 134.9, 132.6, 128.1, 127.9, 125.3, 124.0, 123.3, 117.8, 117.8, 108.8, 54.1, 50.7, 43.6. LRMS (ESI): m/z: anal. calculated for $\left[\mathrm{C}_{21} \mathrm{H}_{21} \mathrm{~F}_{3} \mathrm{~N}_{6}+\mathrm{H}\right]^{+}: 415.2$, found: $415.2 \mathrm{~m} / \mathrm{z}$. HRMS (ESI) m/z: anal. calculated for $\left[\mathrm{C}_{21} \mathrm{H}_{21} \mathrm{~F}_{3} \mathrm{~N}_{6}+\mathrm{H}\right]^{+}:$415.185256, found: 415.18464. LC-MS purity $>99 \%$. 
<smiles>CN1CCN(c2ccc(Nc3nccc(-c4ccncc4)n3)cc2C(F)(F)F)CC1</smiles>

N-(4-(4-methylpiperazin-1-yl)-3-(trifluoromethyl)phenyl)-4-(pyridin-4-yl)pyrimidin-2-amine

General method A, using commercially available (E)-3-(Dimethylamino)-1-(pyridin-4-yl)prop-2-en-1-one. Isolated as a $2 \mathrm{x}$ formate salt. $51 \%$ yield. ${ }^{1} \mathrm{H}$ NMR $(500 \mathrm{MHz}$, Chloroform- $d) \delta 8.82-8.75(\mathrm{~m}, 2 \mathrm{H}), 8.54(\mathrm{~d}, J=$ $5.1 \mathrm{~Hz}, 1 \mathrm{H}), 8.38(\mathrm{~s}, 1 \mathrm{H}), 8.27(\mathrm{~d}, J=2.6 \mathrm{~Hz}, 1 \mathrm{H}), 7.96-7.91(\mathrm{~m}, 2 \mathrm{H}), 7.76(\mathrm{dd}, J=8.7,2.6 \mathrm{~Hz}, 1 \mathrm{H}), 7.42(\mathrm{~d}$, $J=8.6 \mathrm{~Hz}, 1 \mathrm{H}), 7.28-7.24(\mathrm{~m}, 1 \mathrm{H}), 3.19(\mathrm{~s}, 8 \mathrm{H}), 2.77(\mathrm{~s}, 3 \mathrm{H}) .{ }^{13} \mathrm{C}$ NMR $(125 \mathrm{MHz}$, Chloroform- $d) \delta 162.5$, 159.9, 159.2, 150.2, 144.4, 137.7, 128.1, 127.8, 125.3, 123.2, 121.2, 117.8, 117.7, 109.1, 54.1, 50.6, 43.5. LRMS (ESI): $\mathrm{m} / \mathrm{z}$ : anal. calculated for $\left[\mathrm{C}_{21} \mathrm{H}_{21} \mathrm{~F}_{3} \mathrm{~N}_{6}+\mathrm{H}\right]^{+}$: 415.2, found: 415.2. HRMS (ESI) $\mathrm{m} / \mathrm{z}$ : anal. calculated for $\left[\mathrm{C}_{21} \mathrm{H}_{21} \mathrm{~F}_{3} \mathrm{~N}_{6}+\mathrm{H}\right]^{+}$: 415.185256, found: 415.18664. LC-MS purity $>99 \%$.<smiles>CN1CCN(c2ccc(Nc3nccc(-c4ccnc(Cl)c4)n3)cc2C(F)(F)F)CC1</smiles>

4-(2-chloropyridin-4-yl)-N-(4-(4-methylpiperazin-1-yl)-3-(trifluoromethyl)phenyl)pyrimidin-2amine (6) General method A, using (E)-1-(2-Chloro-pyridin-4-yl)-3-dimethylamino-propenone synthesized according to the known procedure. ${ }^{13}$ Isolated as a $2 \mathrm{x}$ formate salt. $34 \%$ yield. ${ }^{1} \mathrm{H} \mathrm{NMR}(500 \mathrm{MHz}$, Chloroform- $d$ ) $\delta 8.58(\mathrm{t}, \mathrm{J}=5.7 \mathrm{~Hz}, 2 \mathrm{H}), 8.30(\mathrm{~s}, 1 \mathrm{H}), 8.03(\mathrm{~s}, 1 \mathrm{H}), 7.98(\mathrm{~s}, 1 \mathrm{H}), 7.84(\mathrm{dd}, \mathrm{J}=5.2,1.7 \mathrm{~Hz}, 1 \mathrm{H})$, $7.72(\mathrm{dd}, \mathrm{J}=8.7,2.6 \mathrm{~Hz}, 1 \mathrm{H}), 7.46(\mathrm{~d}, \mathrm{~J}=8.7 \mathrm{~Hz}, 1 \mathrm{H}), 7.25(\mathrm{dd}, \mathrm{J}=5.1,1.5 \mathrm{~Hz}, 1 \mathrm{H}), 3.23(\mathrm{~s}, 8 \mathrm{H}), 2.81(\mathrm{~s}$, $3 \mathrm{H}) .{ }^{13} \mathrm{C}$ NMR (125 MHz, Chloroform-d) $\delta$ 161.5, 159.9, 159.6, 152.9, 150.7, 147.1, 144.7, 137.4, 125.4, 123.4, 122.0, 119.8, 117.9, 117.9, 109.3, 54.2, 50.6, 43.6. LRMS (ESI): $\mathrm{m} / \mathrm{z}$ : anal. calculated for $\left[\mathrm{C}_{21} \mathrm{H}_{20} \mathrm{ClF}_{3} \mathrm{~N}_{6}+\mathrm{H}\right]^{+}$: 449.1, found: 449.1. HRMS (ESI) $\mathrm{m} / \mathrm{z}$ : anal. calculated for $\left[\mathrm{C}_{21} \mathrm{H}_{20} \mathrm{ClF}_{3} \mathrm{~N}_{6}+\mathrm{H}\right]^{+}$: 449.146283, found: 449.14721. LC-MS purity $>99 \%$.<smiles>CN1CCN(c2ccc(Nc3nccc(-c4ccnc(Cl)c4)n3)cc2C(F)(F)F)CC1</smiles>
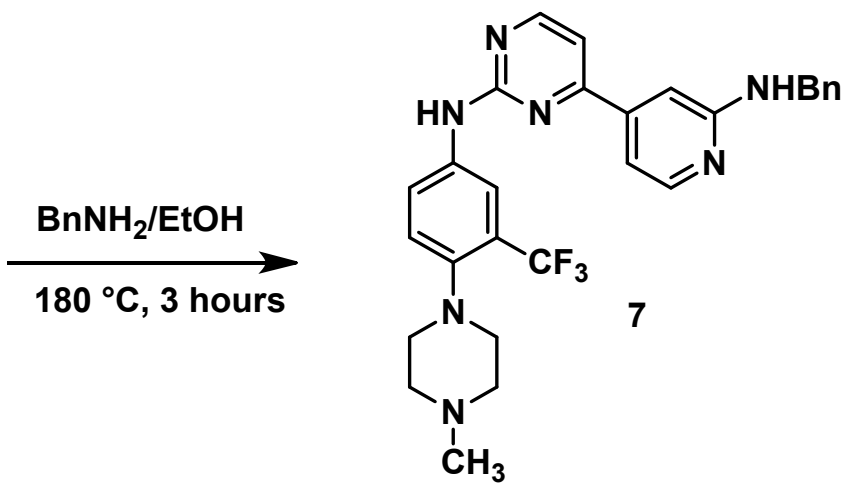
4-(2-(benzylamino)pyridin-4-yl)-N-(4-(4-methylpiperazin-1-yl)-3-

(trifluoromethyl)phenyl)pyrimidin-2-amine (7) To a solution of 4-(2-chloropyridin-4-yl)-N-[4-(4methylpiperazin-1-yl)-3-(trifluoromethyl)phenyl]pyrimidin-2-amine $(50 \mathrm{mg}, 0.111 \mathrm{mmol})$ in EtOH was added 1-phenylmethanamine ( $0.556 \mathrm{mmol}, 5$ equiv.) and stirred at $180{ }^{\circ} \mathrm{C}(\mathrm{MW})$ for $3 \mathrm{~h}$. Isolated as a $2 \mathrm{x}$ formate salt. $27 \%$ yield. ${ }^{1} \mathrm{H}$ NMR $(500 \mathrm{MHz}$, Chloroform- $d) \delta 8.49(\mathrm{~d}, J=5.2 \mathrm{~Hz}, 1 \mathrm{H}), 8.22(\mathrm{~d}, J=2.6 \mathrm{~Hz}, 1 \mathrm{H}), 8.15(\mathrm{~d}, J$ $=5.5 \mathrm{~Hz}, 1 \mathrm{H}), 7.98(\mathrm{~s}, 1 \mathrm{H}), 7.73(\mathrm{dd}, J=8.6,2.6 \mathrm{~Hz}, 1 \mathrm{H}), 7.42-7.33(\mathrm{~m}, 5 \mathrm{H}), 7.31-7.28(\mathrm{~m}, 1 \mathrm{H}), 7.16(\mathrm{dd}, J=$ 5.6, $1.5 \mathrm{~Hz}, 1 \mathrm{H}), 7.13-7.10(\mathrm{~m}, 2 \mathrm{H}), 4.59(\mathrm{~s}, 2 \mathrm{H}), 3.23(\mathrm{~s}, 8 \mathrm{H}), 2.73(\mathrm{~s}, 3 \mathrm{H}) .{ }^{13} \mathrm{C}$ NMR $(125 \mathrm{MHz}$, Chloroform- $d$ ) $\delta$ 163.0, 159.8, 159.1, 158.7, 146.8, 146.5, 144.6, 138.2, 137.5, 128.8, 127.5, 127.3, 125.3, 123.3, 117.8, 117.7, 110.2, 109.4, 105.0, 54.1, 50.7, 46.3, 43.6. LRMS (ESI): $\mathrm{m} / \mathrm{z}$ : anal. calculated for $\left[\mathrm{C}_{28} \mathrm{H}_{28} \mathrm{~F}_{3} \mathrm{~N}_{7}+\mathrm{H}\right]^{+}: 520.2$, found: 520.3. HRMS (ESI) m/z: anal. calculated for $\left[\mathrm{C}_{28} \mathrm{H}_{28} \mathrm{~F}_{3} \mathrm{~N}_{7}+\mathrm{H}\right]^{+}: 520.243105$, found: 520.24169. LCMS purity $>99 \%$.
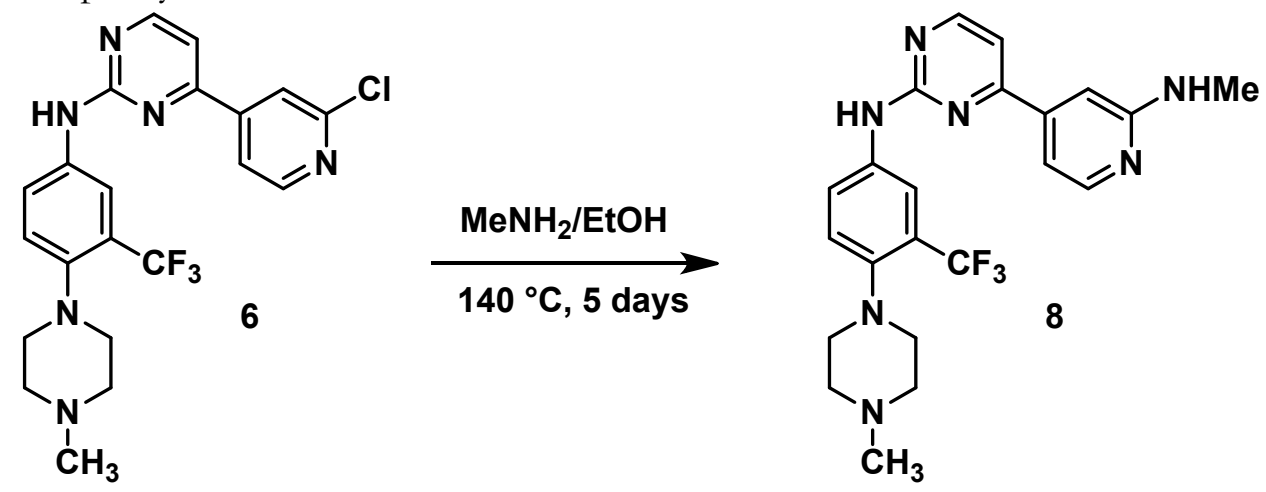

4-(2-(methylamino)pyridin-4-yl)-N-(4-(4-methylpiperazin-1-yl)-3-

(trifluoromethyl)phenyl)pyrimidin-2-amine (8) To a sealed tube was added 4-(2-chloropyridin-4-yl)-N-(4(4-methylpiperazin-1-yl)-3-(trifluoromethyl) phenyl)pyrimidin-2-amine (30 mg, $0.067 \mathrm{mmol}$ ) and 30\% $\mathrm{MeNH}_{2}$ in $\mathrm{EtOH}(10 \mathrm{~mL})$. The mixture was stirred at $140{ }^{\circ} \mathrm{C}$ for 5 days. After the completion of the reaction, the mixture was concentrated under reduced pressure and purified by EZ-prep $(10 \%-25 \% \mathrm{MeCN} /$ water $+0.1 \%$ $\mathrm{HCOOH}$ ), the product was basified with TEA and flushed with 10\% $\mathrm{MeOH} / \mathrm{DCM}$. Yield: $15 \mathrm{mg}$, 51\%; yellowish solid. ${ }^{1} \mathrm{H}$ NMR $(500 \mathrm{MHz}$, Chloroform- $d$ ) $\delta 8.53(\mathrm{~d}, J=5.1 \mathrm{~Hz}, 1 \mathrm{H}), 8.23(\mathrm{~d}, J=5.3 \mathrm{~Hz}, 1 \mathrm{H}), 8.21$ $(\mathrm{d}, J=2.7 \mathrm{~Hz}, 1 \mathrm{H}), 7.69(\mathrm{dd}, J=8.7,2.6 \mathrm{~Hz}, 1 \mathrm{H}), 7.62(\mathrm{~s}, 1 \mathrm{H}), 7.39(\mathrm{~d}, J=8.6 \mathrm{~Hz}, 1 \mathrm{H}), 7.19(\mathrm{~d}, J=5.1 \mathrm{~Hz}$, $1 \mathrm{H}), 7.10(\mathrm{~d}, J=4.7 \mathrm{~Hz}, 2 \mathrm{H}), 4.89(\mathrm{~s}, 1 \mathrm{H}), 3.01(\mathrm{~s}, 3 \mathrm{H}), 2.97(\mathrm{t}, J=4.8 \mathrm{~Hz}, 4 \mathrm{H}), 2.63(\mathrm{~s}, 4 \mathrm{H}), 2.40(\mathrm{~s}, 3 \mathrm{H}) .{ }^{13} \mathrm{C}$ NMR (126 MHz, Chloroform-d) $\delta$ 163.6, 160.5, 160.1, 159.3, 149.1, 146.9, 145.7, 136.7, 128.1 (q, $J=29.0$ $\mathrm{Hz}), 125.0,124.1$ (q, $J=273.6 \mathrm{~Hz}), 123.3,118.1$ (q, $J=5.5 \mathrm{~Hz}), 110.3,109.4$, 103.9, 55.6, 53.4, 46.1, 29.3. LRMS (ESI): $\mathrm{m} / \mathrm{z}$ : anal. calculated for $\left[\mathrm{C}_{22} \mathrm{H}_{24} \mathrm{~F}_{3} \mathrm{~N}_{7}+\mathrm{H}\right]^{+}: 444.2$, found 444.7. HRMS (ESI) m/z: anal. calculated for $\left[\mathrm{C}_{22} \mathrm{H}_{24} \mathrm{~F}_{3} \mathrm{~N}_{7}+\mathrm{H}\right]^{+}$: 444.211805, found 444.21003. LC-MS purity: $97.6 \%$.<smiles>CN1CCN(c2ccc(Nc3nccc(-c4ccccc4)n3)cc2C(F)(F)F)CC1</smiles>

N-(4-(4-methylpiperazin-1-yl)-3-(trifluoromethyl)phenyl)-4-phenylpyrimidin-2-amine (9) General method A, using commercially available (E)-3-(Dimethylamino)-1-phenylprop-2-en-1-one. 85\% yield. ${ }^{1} \mathrm{H}$ NMR (500 MHz, Chloroform-d) $\delta 8.63(\mathrm{~s}, 1 \mathrm{H}), 8.39$ (d, J = $5.3 \mathrm{~Hz}, 1 \mathrm{H}), 8.25$ (d, J = 2.6 Hz, 1H), 8.05-8.00 $(\mathrm{m}, 2 \mathrm{H}), 7.76(\mathrm{dd}, \mathrm{J}=8.7,2.6 \mathrm{~Hz}, 1 \mathrm{H}), 7.49-7.45(\mathrm{~m}, 3 \mathrm{H}), 7.36(\mathrm{~d}, \mathrm{~J}=8.7 \mathrm{~Hz}, 1 \mathrm{H}), 7.17(\mathrm{~d}, \mathrm{~J}=5.2 \mathrm{~Hz}, 1 \mathrm{H})$, 3.15 (s, 8H), 2.75 (s, 3H). ${ }^{13} \mathrm{C}$ NMR (125 MHz, Chloroform-d) $\delta$ 165.4, 159.7, 158.1, 143.9, 138.2, 136.6, 131.3, 
129.0, 128.0, 127.7, 125.2, 123.1, 117.6, 117.6, 108.8, 54.1, 50.6, 43.5. LRMS (ESI): m/z: anal. calculated for $\left[\mathrm{C}_{22} \mathrm{H}_{22} \mathrm{~F}_{3} \mathrm{~N}_{5}+\mathrm{H}\right]^{+}:$414.2, found: 414.0. HRMS (ESI) $\mathrm{m} / \mathrm{z}$ : anal. calculated for $\left[\mathrm{C}_{22} \mathrm{H}_{22} \mathrm{~F}_{3} \mathrm{~N}_{5}+\mathrm{H}\right]^{+}$: 414.190007, found: 414.19193. LC-MS purity 98.6\%.

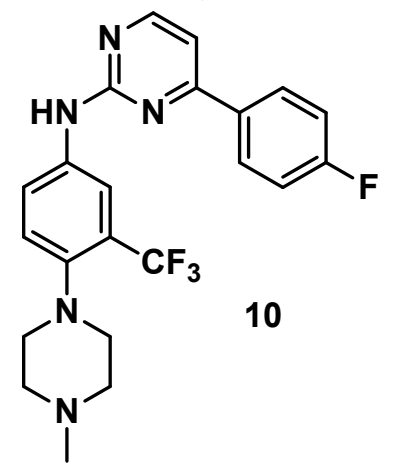

4-(4-fluorophenyl)- $\boldsymbol{N}$-(4-(4-methylpiperazin-1-yl)-3-(trifluoromethyl)phenyl)pyrimidin-2-amine (10) Method B, using commercially available (E)-3-(dimethylamino)-1-(4-fluorophenyl)prop-2-en-1-one. The reaction was performed with (E)-3-(dimethylamino)-1-(4-fluorophenyl)prop-2-en-1-one (77 $\mathrm{mg}, 0.4 \mathrm{mmol}$ ), 1-(4-(4-methylpiperazin-1-yl)-3-(trifluoromethyl)phenyl)guanidine (146 mg, $0.48 \mathrm{mmol}), \mathrm{K}_{2} \mathrm{CO}_{3}$ (276 mg, 2 $\mathrm{mmol})$ and $\mathrm{nBuOH}(5 \mathrm{~mL})$. Eluent: EZ-prep $(10 \%-60 \% \mathrm{MeCN} /$ water $+0.1 \% \mathrm{HCOOH})$ followed by normal phase flash column 5\% MeOH/DCM; yield: $35 \mathrm{mg}, 20 \%$; white solid. ${ }^{1} \mathrm{H}$ NMR (400 MHz, Chloroform-d) $\delta$ $8.47(\mathrm{~d}, J=5.2 \mathrm{~Hz}, 1 \mathrm{H}), 8.18(\mathrm{~d}, J=2.6 \mathrm{~Hz}, 1 \mathrm{H}), 8.11-8.02(\mathrm{~m}, 2 \mathrm{H}), 7.77(\mathrm{~s}, 1 \mathrm{H}), 7.70(\mathrm{dd}, J=8.6,2.6 \mathrm{~Hz}$, $1 \mathrm{H}), 7.37(\mathrm{~d}, J=8.6 \mathrm{~Hz}, 1 \mathrm{H}), 7.22-7.11(\mathrm{~m}, 3 \mathrm{H}), 2.97(\mathrm{t}, J=4.7 \mathrm{~Hz}, 4 \mathrm{H}), 2.61(\mathrm{~s}, 4 \mathrm{H}), 2.39(\mathrm{~s}, 3 \mathrm{H}) .{ }^{13} \mathrm{C}$ NMR $(101 \mathrm{MHz}$, Chloroform- $d) \delta 164.8(\mathrm{~d}, J=251.6 \mathrm{~Hz}), 164.0,160.1,158.8,146.8,136.9,133.0(\mathrm{~d}, J=3.0 \mathrm{~Hz})$, $129.3(\mathrm{~d}, J=8.7 \mathrm{~Hz}), 128.0(\mathrm{q}, J=28.6 \mathrm{~Hz}), 125.0,124.0(\mathrm{q}, J=273.4 \mathrm{~Hz}), 123.1,118.0(\mathrm{q}, J=5.8 \mathrm{~Hz}), 116.1$ $(\mathrm{d}, J=21.8 \mathrm{~Hz}), 108.5,55.6,53.5,46.2$. LRMS (ESI): $\mathrm{m} / \mathrm{z}$ : anal. calculated for $\left[\mathrm{C}_{22} \mathrm{H}_{21} \mathrm{~F}_{4} \mathrm{~N}_{5}+\mathrm{H}\right]^{+}$: 432.2, found 432.1. HRMS (ESI) $\mathrm{m} / \mathrm{z}$ : anal. calculated for $\left[\mathrm{C}_{22} \mathrm{H}_{21} \mathrm{~F}_{4} \mathrm{~N}_{5}+\mathrm{H}\right]^{+}:$432.180585, found 432.18013. LCMS purity: $97.0 \%$.

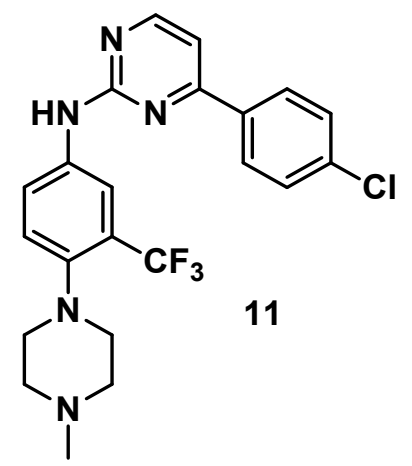

4-(4-chlorophenyl)-N-(4-(4-methylpiperazin-1-yl)-3-(trifluoromethyl)phenyl)pyrimidin-2-amine (11) General method A, using commercially available (E)-1-(4-chlorophenyl)-3-(dimethylamino)prop-2-en-1-one. $57 \%$ yield. ${ }^{1} \mathrm{H}$ NMR $(500 \mathrm{MHz}$, Chloroform- $d$ ) $\delta 8.47$ (d, J = 5.2 Hz, 1H), $8.27(\mathrm{~d}, \mathrm{~J}=2.6 \mathrm{~Hz}, 1 \mathrm{H}), 8.04-8.01$ $(\mathrm{m}, 2 \mathrm{H}), 7.74(\mathrm{dd}, \mathrm{J}=8.6,2.6 \mathrm{~Hz}, 1 \mathrm{H}), 7.69(\mathrm{~s}, 1 \mathrm{H}), 7.51-7.48(\mathrm{~m}, 2 \mathrm{H}), 7.44(\mathrm{~d}, \mathrm{~J}=8.7 \mathrm{~Hz}, 1 \mathrm{H}), 7.19(\mathrm{~d}, \mathrm{~J}=$ $5.3 \mathrm{~Hz}, 1 \mathrm{H}), 3.17$ (s, 8H), 2.70 (s, 3H). ${ }^{13} \mathrm{C}$ NMR $(100 \mathrm{MHz}$, Chloroform- $d$ ) $\delta$ 163.8, 160.0, 158.9, 146.9, 137.2, 136.6, 135.3, 129.2, 128.4, 117.8, 117.8, 108.6, 55.6, 53.6, 46.2. LRMS (ESI): $\mathrm{m} / \mathrm{z}$ : anal. calculated for $\left[\mathrm{C}_{22} \mathrm{H}_{21} \mathrm{ClF}_{3} \mathrm{~N}_{5}+\mathrm{H}\right]^{+}$: 448.2, found: 448.0. HRMS (ESI) m/z: anal. calculated for $\left[\mathrm{C}_{22} \mathrm{H}_{21} \mathrm{ClF}_{3} \mathrm{~N}_{5}+\mathrm{H}\right]^{+}$: 448.151034, found: 448.15015. LC-MS purity $96.2 \%$. 


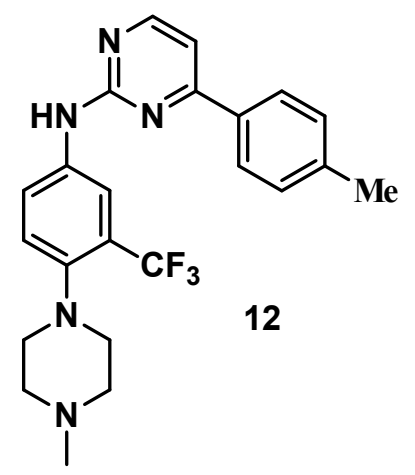

N-(4-(4-methylpiperazin-1-yl)-3-(trifluoromethyl)phenyl)-4-(p-tolyl)pyrimidin-2-amine (12) Method $\mathrm{B}$, using commercially available (E)-3-(dimethylamino)-1-(4-methylphenyl)-2-propen-1-one. The reaction was performed with (E)-3-(dimethylamino)-1-(p-tolyl)prop-2-en-1-one (38 mg, 0.2 mmol), 1-(4-(4methylpiperazin-1-yl)-3-(trifluoromethyl)phenyl)guanidine (73 mg, $0.24 \mathrm{mmol}$ ), K2CO3 (276 mg, $2 \mathrm{mmol}$ ) and $\mathrm{nBuOH}(5 \mathrm{~mL})$. Eluent: EZ-prep (10\% - 60\% MeCN/water+0.1\% HCOOH); yield: $16 \mathrm{mg}, 19 \%$; white/brownish solid. 1H NMR (400 MHz, Chloroform- $d$ ) $\delta 8.45(\mathrm{~d}, \mathrm{~J}=5.3 \mathrm{~Hz}, 1 \mathrm{H}), 8.23(\mathrm{~d}, \mathrm{~J}=2.6 \mathrm{~Hz}$, 1H), $7.98(\mathrm{~d}, \mathrm{~J}=7.9 \mathrm{~Hz}, 2 \mathrm{H}), 7.74(\mathrm{dd}, \mathrm{J}=8.6,2.6 \mathrm{~Hz}, 1 \mathrm{H}), 7.69(\mathrm{~s}, 1 \mathrm{H}), 7.39(\mathrm{~d}, \mathrm{~J}=8.7 \mathrm{~Hz}, 1 \mathrm{H}), 7.31$ (d, J $=7.9 \mathrm{~Hz}, 2 \mathrm{H}), 7.19(\mathrm{~d}, \mathrm{~J}=5.2 \mathrm{~Hz}, 1 \mathrm{H}), 3.27-3.00(\mathrm{~m}, 4 \mathrm{H}), 2.82(\mathrm{~s}, 4 \mathrm{H}), 2.51(\mathrm{~s}, 3 \mathrm{H}), 2.43(\mathrm{~s}, 3 \mathrm{H}) .13 \mathrm{C}$ NMR (101 MHz, Chloroform- $d$ ) $\delta$ 165.2, 160.0, 158.5, 145.7, 141.6, 137.5, 134.1, 129.8, 128.1 (q, J = 28.5 Hz), 127.2 , 125.1, 124.0 (q, J = 273.5 Hz), 123.0, 117.7 (q, J = 5.8 Hz), 108.7, 54.9, 52.4, 45.1, 21.6. LRMS (ESI): m/z: anal. calculated for $\left[\mathrm{C}_{23} \mathrm{H}_{24} \mathrm{~F}_{3} \mathrm{~N}_{5}+\mathrm{H}\right]^{+}$: 428.2, found 428.1. HRMS (ESI) $\mathrm{m} / \mathrm{z}$ : anal. calculated for $\left[\mathrm{C}_{23} \mathrm{H}_{24} \mathrm{~F}_{3} \mathrm{~N}_{5}+\mathrm{H}\right]^{+}:$428.205657, found 428.20399. LC-MS purity: $>99 \%$.

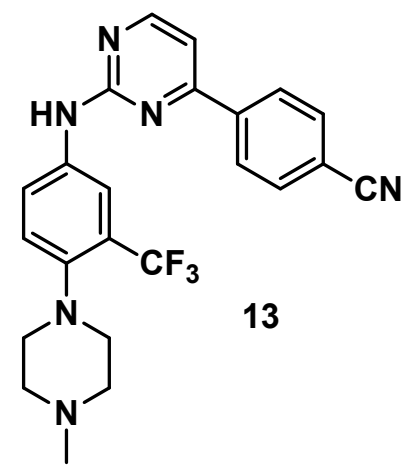

4-(2-((4-(4-methylpiperazin-1-yl)-3-(trifluoromethyl)phenyl)amino)pyrimidin-4-yl)benzonitrile (13) Method B, using (E)-3-(3-(dimethylamino)acryloyl)benzonitrile synthesized according to the known procedure. ${ }^{14}$ The reaction was performed with (E)-3-(3-(dimethylamino)acryloyl)benzonitrile (80 mg, 0.4 mmol), 1-(4-(4-methylpiperazin-1-yl)-3-(trifluoromethyl)phenyl)guanidine (146 mg, $0.48 \mathrm{mmol}$, $\mathrm{K}_{2} \mathrm{CO}_{3}(276$ $\mathrm{mg}, 2 \mathrm{mmol}$ ) and $\mathrm{nBuOH}(5 \mathrm{~mL})$. Eluent: 1\% - 5\% MeOH/DCM followed by recrystallization with Acetone/Hexane; yield: $13 \mathrm{mg}, 8 \%$; yellowish solid. ${ }^{1} \mathrm{H}$ NMR $(400 \mathrm{MHz}$, Chloroform- $d) \delta 8.56(\mathrm{~d}, J=5.1 \mathrm{~Hz}$, $1 \mathrm{H}), 8.26-8.12(\mathrm{~m}, 3 \mathrm{H}), 7.87-7.76(\mathrm{~m}, 2 \mathrm{H}), 7.69(\mathrm{dd}, J=8.6,2.7 \mathrm{~Hz}, 1 \mathrm{H}), 7.49(\mathrm{~s}, 1 \mathrm{H}), 7.40(\mathrm{~d}, J=8.6 \mathrm{~Hz}$, $1 \mathrm{H}), 7.22(\mathrm{~d}, J=5.1 \mathrm{~Hz}, 1 \mathrm{H}), 2.96(\mathrm{t}, J=4.7 \mathrm{~Hz}, 4 \mathrm{H}), 2.59(\mathrm{~s}, 4 \mathrm{H}), 2.38(\mathrm{~s}, 3 \mathrm{H}) .{ }^{13} \mathrm{C} \mathrm{NMR}(101 \mathrm{MHz}$, Chloroform- $d$ ) $\delta$ 163.0, 160.2, 159.5, 147.3, 141.1, 136.4, 132.8, 128.1 (q, $J=28.6 \mathrm{~Hz}), 127.8,125.0,124.0$ (q, $J=273.5 \mathrm{~Hz}$ ), 123.3, 118.5, 118.1 (q, $J=5.6 \mathrm{~Hz}), 114.5,109.2,55.6,53.7,46.3$. LRMS (ESI): $\mathrm{m} / \mathrm{z}:$ anal. calculated for $\left[\mathrm{C}_{23} \mathrm{H}_{21} \mathrm{~F}_{3} \mathrm{~N}_{6}+\mathrm{H}\right]^{+}: 439.2$, found 439.1. HRMS (ESI) m/z: anal. calculated for $\left[\mathrm{C}_{23} \mathrm{H}_{21} \mathrm{~F}_{3} \mathrm{~N}_{6}+\right.$ $\mathrm{H}]^{+}$: 439.185256, found 439.18449. LC-MS purity: $>99 \%$. 


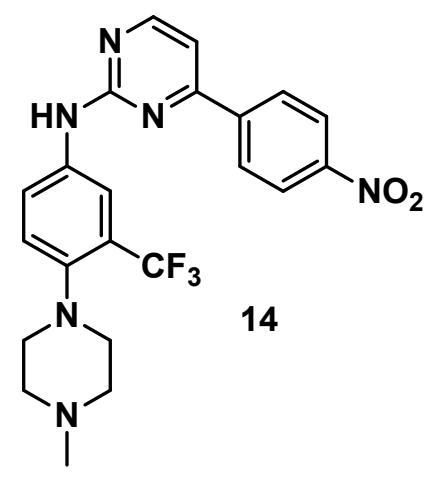

N-(4-(4-methylpiperazin-1-yl)-3-(trifluoromethyl)phenyl)-4-(4-nitrophenyl)pyrimidin-2-amine (14) General method A, using commercially available (E)-3-(dimethylamino)-1-(4-nitrophenyl)prop-2-en-1-one. Isolated as a $2 \mathrm{x}$ formate salt. $43 \%$ yield. ${ }^{1} \mathrm{H}$ NMR $(500 \mathrm{MHz}$, Dimethyl sulfoxide- $d 6) \delta 8.70(\mathrm{~d}, \mathrm{~J}=5.1 \mathrm{~Hz}$, $1 \mathrm{H}), 8.41$ (q, J = 9.0 Hz, 4H), $8.32(\mathrm{~s}, 1 \mathrm{H}), 8.26(\mathrm{~s}, 1 \mathrm{H}), 8.04(\mathrm{~d}, \mathrm{~J}=8.8 \mathrm{~Hz}, 1 \mathrm{H}), 7.60(\mathrm{~d}, \mathrm{~J}=5.2 \mathrm{~Hz}, 1 \mathrm{H})$, $7.56(\mathrm{~d}, \mathrm{~J}=8.8 \mathrm{~Hz}, 1 \mathrm{H}), 2.87(\mathrm{~s}, 4 \mathrm{H}), 2.53(\mathrm{~s}, 4 \mathrm{H}), 2.28(\mathrm{~s}, 3 \mathrm{H}) \cdot{ }^{13} \mathrm{C}$ NMR (125 MHz, Dimethyl sulfoxide-d6) $\delta$ 161.9, 160.4, 149.3, 146.1, 143.0, 138.1, 128.7, 126.5, 126.3, 125.5, 124.4, 123.7, 117.2, 117.1, 109.8, 55.5, 53.5, 46.1. LRMS (ESI): $\mathrm{m} / \mathrm{z}$ : anal. calculated for $\left[\mathrm{C}_{22} \mathrm{H}_{21} \mathrm{~F}_{3} \mathrm{~N}_{6} \mathrm{O}_{2}+\mathrm{H}\right]^{+}: 459.2$, found: 459.2. HRMS (ESI) $\mathrm{m} / \mathrm{z}$ : anal. calculated for $\left[\mathrm{C}_{22} \mathrm{H}_{21} \mathrm{~F}_{3} \mathrm{~N}_{6} \mathrm{O}_{2}+\mathrm{H}\right]^{+}$: 459.175085, found: 459.17553. LC-MS purity $>99 \%$.

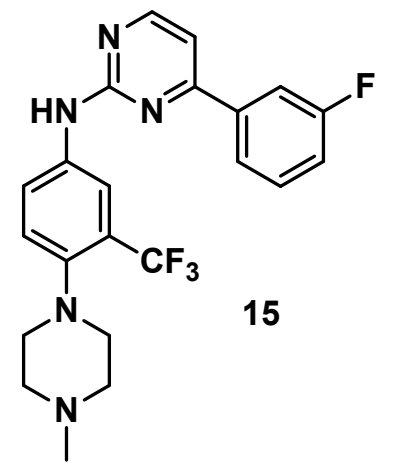

4-(3-fluorophenyl)- $\mathbf{N}$-(4-(4-methylpiperazin-1-yl)-3-(trifluoromethyl)phenyl)pyrimidin-2-amine (15) Method B, using (E)-3-(dimethylamino)-1-(3-fluorophenyl)prop-2-en-1-one synthesized according to the known procedure. ${ }^{15}$ The reaction was performed with (E)-3-(dimethylamino)-1-(3-fluorophenyl)prop-2-en-1-

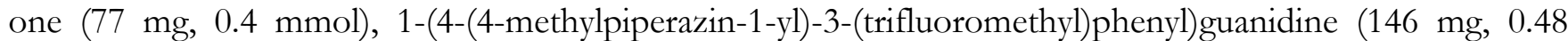
mmol), $\mathrm{K}_{2} \mathrm{CO}_{3}(276 \mathrm{mg}, 2 \mathrm{mmol})$ and $\mathrm{nBuOH}(5 \mathrm{~mL})$. Eluent: 1\% - 5\% MeOH/DCM; yield: $29 \mathrm{mg}, 17 \%$; white solid. ${ }^{1} \mathrm{H}$ NMR (400 MHz, Chloroform- $\left.d\right) \delta 8.50(\mathrm{~d}, J=5.3 \mathrm{~Hz}, 1 \mathrm{H}), 8.17(\mathrm{~d}, J=2.6 \mathrm{~Hz}, 1 \mathrm{H}), 7.85$ (dd, $J=7.9,1.4 \mathrm{~Hz}, 1 \mathrm{H}), 7.79(\mathrm{dt}, J=10.0,2.2 \mathrm{~Hz}, 1 \mathrm{H}), 7.73(\mathrm{dd}, J=8.7,2.6 \mathrm{~Hz}, 1 \mathrm{H}), 7.52-7.43(\mathrm{~m}, 2 \mathrm{H}), 7.40$ $(\mathrm{d}, J=8.7 \mathrm{~Hz}, 1 \mathrm{H}), 7.24-7.14(\mathrm{~m}, 2 \mathrm{H}), 2.99(\mathrm{t}, J=4.8 \mathrm{~Hz}, 4 \mathrm{H}), 2.64(\mathrm{~s}, 4 \mathrm{H}), 2.41(\mathrm{~s}, 3 \mathrm{H}) .{ }^{13} \mathrm{C}$ NMR $(101$ $\mathrm{MHz}$, Chloroform-d) $\delta 163.8(\mathrm{~d}, J=2.6 \mathrm{~Hz}), 163.4(\mathrm{~d}, J=246.4 \mathrm{~Hz}), 160.1,159.1,146.8,139.3(\mathrm{~d}, J=7.6$ $\mathrm{Hz}), 136.8,130.6(\mathrm{~d}, J=8.0 \mathrm{~Hz}), 128.1(\mathrm{q}, J=28.6 \mathrm{~Hz}), 125.1,124.0(\mathrm{q}, J=273.3 \mathrm{~Hz}), 123.2,122.8(\mathrm{~d}, J=$ $2.9 \mathrm{~Hz}), 118.0(\mathrm{q}, J=5.6 \mathrm{~Hz}), 118.0(\mathrm{~d}, J=21.2 \mathrm{~Hz}), 114.2(\mathrm{~d}, J=23.1 \mathrm{~Hz}), 109.0,55.6,53.4$, 46.1. LRMS (ESI): $\mathrm{m} / \mathrm{z}$ : anal. calculated for $\left[\mathrm{C}_{22} \mathrm{H}_{21} \mathrm{~F}_{4} \mathrm{~N}_{5}+\mathrm{H}\right]^{+}:$432.2, found 432.0. HRMS (ESI) $\mathrm{m} / \mathrm{z}$ : anal. calculated for $\left[\mathrm{C}_{22} \mathrm{H}_{21} \mathrm{~F}_{4} \mathrm{~N}_{5}+\mathrm{H}\right]^{+}$: 432.180585, found 432.18198. LC-MS purity: $96.6 \%$. 
<smiles>CN1CCN(c2ccc(Nc3nccc(-c4cccc(Cl)c4)n3)cc2C(F)(F)F)CC1</smiles>

4-(3-chlorophenyl)-N-(4-(4-methylpiperazin-1-yl)-3-(trifluoromethyl)phenyl)pyrimidin-2-amine (16) General method A, using commercially available (E)-1-(3-chlorophenyl)-3-(dimethylamino)prop-2-en-1-one. $78 \%$ yield. ${ }^{1} \mathrm{H}$ NMR $(500 \mathrm{MHz}$, Chloroform- $d) \delta 8.45(\mathrm{~s}, 1 \mathrm{H}), 8.26(\mathrm{~d}, \mathrm{~J}=2.7 \mathrm{~Hz}, 2 \mathrm{H}), 8.03(\mathrm{~s}, 1 \mathrm{H}), 7.90(\mathrm{~d}$, $\mathrm{J}=7.5 \mathrm{~Hz}, 1 \mathrm{H}), 7.70(\mathrm{dd}, \mathrm{J}=8.7,2.6 \mathrm{~Hz}, 1 \mathrm{H}), 7.48-7.35(\mathrm{~m}, 3 \mathrm{H}), 7.15(\mathrm{~d}, \mathrm{~J}=5.2 \mathrm{~Hz}, 1 \mathrm{H}), 3.16(\mathrm{~s}, 8 \mathrm{H}), 2.73$ (s, 3H). ${ }^{13} \mathrm{C}$ NMR $(125 \mathrm{MHz}$, Chloroform-d) $\delta$ 163.7, 160.0, 159.0, 146.9, 138.7, 136.6, 135.2, 131.0, 130.2, 128.2, 128.0, 127.4, 125.2, 124.9, 123.1, 118.0, 117.9, 108.8, 55.5, 53.5, 46.1. LRMS (ESI): $\mathrm{m} / \mathrm{z}$ : anal. calculated for $\left[\mathrm{C}_{22} \mathrm{H}_{21} \mathrm{ClF}_{3} \mathrm{~N}_{5}+\mathrm{H}\right]^{+}$: 448.2, found: 448.0. HRMS (ESI) m/z: anal. calculated for $\left[\mathrm{C}_{22} \mathrm{H}_{21} \mathrm{ClF}_{3} \mathrm{~N}_{5}+\mathrm{H}\right]^{+}$: 448.151034, found: 448.15016. LC-MS purity $>99 \%$.<smiles>COc1cccc(-c2ccnc(Nc3ccc(N4CCN(C)CC4)c(C(F)(F)F)c3)n2)c1</smiles>

4-(3-methoxyphenyl)-N-(4-(4-methylpiperazin-1-yl)-3-(trifluoromethyl)phenyl)pyrimidin-2-amine (17) General method A, using commercially available (E)-3-(Dimethylamino)-1-(3-methoxyphenyl)prop-2-en1-one. Isolated as a 1.5x formate salt. $48 \%$ yield. ${ }^{1} \mathrm{H}$ NMR (500 MHz, Chloroform- $d$ ) $\delta 8.37(\mathrm{~d}, \mathrm{~J}=5.3 \mathrm{~Hz}$, $1 \mathrm{H}), 8.31(\mathrm{~s}, 1 \mathrm{H}), 8.23(\mathrm{~m}, 1 \mathrm{H}), 8.03(\mathrm{~d}, \mathrm{~J}=8.7 \mathrm{~Hz}, 2 \mathrm{H}), 7.80-7.75(\mathrm{~m}, 1 \mathrm{H}), 7.38(\mathrm{~d}, \mathrm{~J}=8.6 \mathrm{~Hz}, 1 \mathrm{H}), 7.13(\mathrm{~d}$, $\mathrm{J}=5.3 \mathrm{~Hz}, 1 \mathrm{H}), 6.99(\mathrm{~d}, \mathrm{~J}=8.7 \mathrm{~Hz}, 2 \mathrm{H}), 3.86(\mathrm{~s}, 3 \mathrm{H}), 3.14(\mathrm{br}, 8 \mathrm{H}), 2.69(\mathrm{~s}, 3 \mathrm{H}) .{ }^{13} \mathrm{C} \mathrm{NMR}(125 \mathrm{MHz}$, Chloroform-d) $\delta 164.8,162.3,159.6,157.9,144.3,138.1,129.0,128.8,128.0,127.8,125.1,123.1,117.6,117.6$, 114.4, 108.0, 55.5, 54.2, 50.9, 43.7. LRMS (ESI): $\mathrm{m} / \mathrm{z}$ : anal. calculated for $\left[\mathrm{C}_{23} \mathrm{H}_{24} \mathrm{~F}_{3} \mathrm{~N}_{5} \mathrm{O}+\mathrm{H}\right]^{+}$: 444.2, found: 444.0. HRMS (ESI) $\mathrm{m} / \mathrm{z}$ : anal. calculated for $\left[\mathrm{C}_{23} \mathrm{H}_{24} \mathrm{~F}_{3} \mathrm{~N}_{5} \mathrm{O}+\mathrm{H}\right]^{+}: 444.200572$, found: 444.20138. LC-MS purity $97.1 \%$.<smiles>CN1CCN(c2ccc(Nc3nccc(-c4cccc(C#N)c4)n3)cc2C(F)(F)F)CC1</smiles>

3-(2-((4-(4-methylpiperazin-1-yl)-3-(trifluoromethyl)phenyl)amino)pyrimidin-4-yl)benzonitrile (18) Method B, using (E)-3-(3-(dimethylamino)acryloyl)benzonitrile synthesized according to the known procedure. ${ }^{16}$ The reaction was performed with (E)-3-(3-(dimethylamino)acryloyl)benzonitrile $(80 \mathrm{mg}, 0.4$ 
mmol), 1-(4-(4-methylpiperazin-1-yl)-3-(trifluoromethyl)phenyl)guanidine (146 mg, 0.48 mmol), $\mathrm{K}_{2} \mathrm{CO}_{3}(276$ $\mathrm{mg}, 2 \mathrm{mmol}$ ) and $\mathrm{nBuOH}(5 \mathrm{~mL})$. Eluent: 1\% - 5\% MeOH/DCM followed by recrystallization with DCM/Hexane; yield: $22 \mathrm{mg}, 13 \%$; yellowish solid. ${ }^{1} \mathrm{H}$ NMR $(400 \mathrm{MHz}$, Chloroform- $d$ ) $\delta 8.55(\mathrm{~d}, J=5.2 \mathrm{~Hz}$, $1 \mathrm{H}), 8.36(\mathrm{t}, J=1.7 \mathrm{~Hz}, 1 \mathrm{H}), 8.31(\mathrm{dt}, J=8.0,1.5 \mathrm{~Hz}, 1 \mathrm{H}), 8.16(\mathrm{~d}, J=2.6 \mathrm{~Hz}, 1 \mathrm{H}), 7.78(\mathrm{dt}, J=7.8,1.4 \mathrm{~Hz}$, $1 \mathrm{H}), 7.70(\mathrm{dd}, J=8.6,2.7 \mathrm{~Hz}, 1 \mathrm{H}), 7.63(\mathrm{t}, J=7.8 \mathrm{~Hz}, 1 \mathrm{H}), 7.54(\mathrm{~s}, 1 \mathrm{H}), 7.40(\mathrm{~d}, J=8.7 \mathrm{~Hz}, 1 \mathrm{H}), 7.19(\mathrm{~d}, J=$ $5.2 \mathrm{~Hz}, 1 \mathrm{H}), 2.96(\mathrm{t}, J=4.7 \mathrm{~Hz}, 4 \mathrm{H}), 2.59(\mathrm{~s}, 4 \mathrm{H}), 2.37(\mathrm{~s}, 3 \mathrm{H}) \cdot{ }^{13} \mathrm{C}$ NMR $(101 \mathrm{MHz}$, Chloroform-d) $\delta 162.7$, $160.2,159.5,147.3,138.2,136.4,134.1,131.3,130.9,129.9,128.1$ (q, $J=28.6 \mathrm{~Hz}), 125.0,124.0$ (q, $J=273.5$ $\mathrm{Hz}), 123.3,118.4,118.2(\mathrm{q}, J=5.8 \mathrm{~Hz}), 113.5,108.7,55.6,53.6$, 46.3. LRMS (ESI): $\mathrm{m} / \mathrm{z}$ : anal. calculated for $\left[\mathrm{C}_{23} \mathrm{H}_{21} \mathrm{~F}_{3} \mathrm{~N}_{6}+\mathrm{H}\right]^{+}$: 439.2, found 439.1. HRMS (ESI) $\mathrm{m} / \mathrm{z}$ : anal. calculated for $\left[\mathrm{C}_{23} \mathrm{H}_{21} \mathrm{~F}_{3} \mathrm{~N}_{6}+\mathrm{H}\right]^{+}$: 439.185256, found 439.18502. LC-MS purity: $98.84 \%$.<smiles>CN1CCN(c2ccc(Nc3nccc(-c4cccc([N+](=O)[O-])c4)n3)cc2C(F)(F)F)CC1</smiles>

N-(4-(4-methylpiperazin-1-yl)-3-(trifluoromethyl)phenyl)-4-(3-nitrophenyl)pyrimidin-2-amine (19) General method A, using commercially available (E)-3-(dimethylamino)-1-(3-nitrophenyl)-2-propen-1-one. Isolated as a $1.5 \mathrm{x}$ formate salt. $27 \%$ yield. ${ }^{1} \mathrm{H}$ NMR $(500 \mathrm{MHz}$, Chloroform-d) $\delta 8.88(\mathrm{~s}, 1 \mathrm{H}), 8.55(\mathrm{~d}, \mathrm{~J}=5.2$ $\mathrm{Hz}, 1 \mathrm{H}), 8.42(\mathrm{~d}, \mathrm{~J}=7.8 \mathrm{~Hz}, 1 \mathrm{H}), 8.36-8.33(\mathrm{~m}, 2 \mathrm{H}), 8.22-8.21(\mathrm{~m}, 1 \mathrm{H}), 8.03(\mathrm{~s}, 1 \mathrm{H}), 7.76(\mathrm{dd}, \mathrm{J}=8.6,2.1 \mathrm{~Hz}$, $1 \mathrm{H}), 7.70(\mathrm{t}, \mathrm{J}=8.0 \mathrm{~Hz}, 1 \mathrm{H}), 7.43(\mathrm{~d}, \mathrm{~J}=8.6 \mathrm{~Hz}, 1 \mathrm{H}), 7.28(\mathrm{~d}, \mathrm{~J}=5.2 \mathrm{~Hz}, 1 \mathrm{H}), 3.18(\mathrm{~s}, 8 \mathrm{H}), 2.73(\mathrm{~s}, 2 \mathrm{H}) .{ }^{13} \mathrm{C}$ NMR (125 MHz, Chloroform-d) $\delta$ 162.6, 160.0, 159.3, 148.9, 144.8, 138.5, 137.5, 132.8, 130.1, 128.2, 128.0, 125.5, 125.3, 123.4, 122.1, 117.9, 117.9, 108.9, 54.1, 50.8, 43.7. LRMS (ESI): $\mathrm{m} / \mathrm{z}$ : anal. calculated for $\left[\mathrm{C}_{22} \mathrm{H}_{21} \mathrm{~F}_{3} \mathrm{~N}_{6} \mathrm{O}_{2}+\mathrm{H}\right]^{+}:$459.2, found: 459.1. HRMS (ESI) $\mathrm{m} / \mathrm{z}$ : anal. calculated for $\left[\mathrm{C}_{22} \mathrm{H}_{21} \mathrm{~F}_{3} \mathrm{~N}_{6} \mathrm{O}_{2}+\mathrm{H}\right]^{+}$: 459.175085, found: 459.17372. LC-MS purity $96.5 \%$.

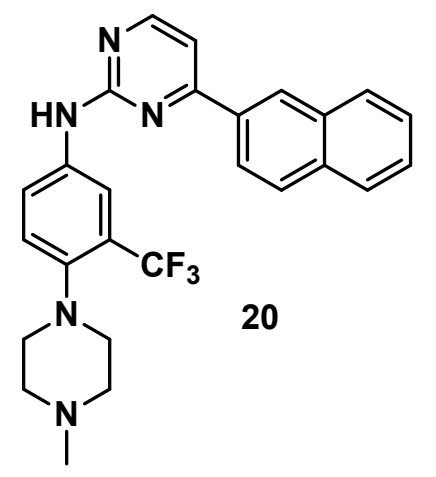

N-(4-(4-methylpiperazin-1-yl)-3-(trifluoromethyl)phenyl)-4-(naphthalen-2-yl)pyrimidin-2-amine (20) General method A, using commercially available (E)-3-(Dimethylamino)-1-(2-naphthyl)-2-propen-1-one. Isolated as a $1.5 \mathrm{x}$ formate salt. $57 \%$ yield. ${ }^{1} \mathrm{H}$ NMR $(500 \mathrm{MHz}$, Chloroform- $d) \delta 8.59(\mathrm{~s}, 1 \mathrm{H}), 8.48-8.44(\mathrm{~m}$, $3 \mathrm{H}), 8.10(\mathrm{~d}, \mathrm{~J}=8.4 \mathrm{~Hz}, 1 \mathrm{H}), 7.94(\mathrm{t}, \mathrm{J}=8.8 \mathrm{~Hz}, 2 \mathrm{H}), 7.85(\mathrm{~d}, \mathrm{~J}=5.0 \mathrm{~Hz}, 1 \mathrm{H}), 7.70(\mathrm{~d}, \mathrm{~J}=7.8 \mathrm{~Hz}, 1 \mathrm{H}), 7.56-$ $7.51(\mathrm{~m}, 2 \mathrm{H}), 7.38(\mathrm{~d}, \mathrm{~J}=8.5 \mathrm{~Hz}, 1 \mathrm{H}), 7.32(\mathrm{~d}, \mathrm{~J}=5.1 \mathrm{~Hz}, 1 \mathrm{H}), 3.16(\mathrm{~s}, 8 \mathrm{H}), 2.73(\mathrm{~s}, 3 \mathrm{H}) .{ }^{13} \mathrm{C}$ NMR $(125$ $\mathrm{MHz}$, Chloroform-d) $\delta$ 165.2, 159.7, 158.1, 144.2, 138.1, 134.8, 133.8, 133.2, 129.2, 128.8, 127.8, 127.7, 127.6, 126.8, 125.1, 123.8, 123.1, 117.7, 117.7, 109.0, 54.1, 50.7, 43.6. LRMS (ESI): $\mathrm{m} / \mathrm{z}$ : anal. calculated for $\left[\mathrm{C}_{26} \mathrm{H}_{24} \mathrm{~F}_{3} \mathrm{~N}_{5}+\mathrm{H}\right]^{+}:$464.2, found: 464.1. HRMS (ESI) $\mathrm{m} / \mathrm{z}$ : anal. calculated for $\left[\mathrm{C}_{26} \mathrm{H}_{24} \mathrm{~F}_{3} \mathrm{~N}_{5}+\mathrm{H}\right]^{+}$: 464.205657, found: 464.20518. LC-MS purity $>99 \%$. 
E. Biochemical activity $\&$ affinity assays: New compounds were tested for activity against recombinant PknB using the ATP Glo ${ }^{\circledR}$ assay following previously published procedures ${ }^{1}$. Compounds were titrated 2fold from 20 to $0 \mu \mathrm{M}$ in 8-point serial dilutions. Activity on Cdk2-Cyclin A was done similarly except the starting concentration was $40 \mu \mathrm{M}$ and myelin basic protein (MBP, Sigma) was used as a substrate at a concentration of $50 \mu \mathrm{M}$ and $\mathrm{Cdk} 2$-Cyclin A was used at a concentration of $1 \mu \mathrm{M}$. All inhibitors for biochemical assays were diluted in DMSO prior to addition to buffer to ensure any precipitation did not affect subsequent wells in the series. Wells with visible precipitation were excluded from analysis. Data were processed in GraphPad PRISM and $\mathrm{IC}_{50}$ and $\mathrm{K}_{\mathrm{i}}$ values for $\mathrm{PknB}$ were determined as previously published ${ }^{1}$.

Biochemical affinity for aminopyrimidines towards $\mathrm{PknB}$ was performed using microscale thermophoresis using a Nano'Temper Monolith NT115. N-terminal HIS-tagged PknB 1-331 was cloned into a PQlink H vector by digesting the insert PQlink $\mathrm{G}$ construct with BamHI and NotI and ligating with T4 ligase following manufacturer procedures (New England Biolabs). The construct was transformed into DH5 $\alpha$ cells and purified as previously reported ${ }^{1}$, substituting Ni-NTA columns for GS4FF columns and eluting with $250 \mathrm{mM}$ imidazole instead of reduced glutathione. The HIS tag was not digested from the purified protein but was instead complexed to a fluorophore using the Nanotemper His-Tag Labeling Kit RED-tris-NTA 2nd Generation kit following manufacturer instructions. Inhibitors were serially diluted 2-fold with a 16-point titration curve starting at $3200 \mathrm{nM}$ in a buffer containing 10mM HEPES pH 7.4, $150 \mathrm{mM} \mathrm{NaCl}, 1 \mathrm{mM} \mathrm{MgCl} 2$, $1 \mathrm{mM} \mathrm{DTT}$, and $0.05 \%$ Tween 20 . The final concentration of DMSO was 3.2\%. Labeled HIS-PknB was added in the same buffer at a final concentration of $20 \mathrm{nM}$. Samples were drawn into standard capillary tubes and placed in the machine where the fluorophore was excited at medium power with $5 \%$ excitation. Fluorescence intensity variation and adsorption was measured before and after thermophoresis measurements, and a dose response was plotted and $\mathrm{K}_{\mathrm{d}}$ calculated using the MO.Control v1.6 software. Samples showing variation in fluorescence intensity, having adsorption, or having aggregation were excluded.

Biochemical affinity testing for human kinases and PknB was conducted by DiscoverX/Eurofins using the KinomeSCAN panel and screening compounds at $10 \mu \mathrm{M}$ following commercial procedures. Compounds and kinases selected for follow-up were assessed using the same commercial assay in a different format (KinaseELECT) which uses 11-point 3-fold serial dilutions starting at $10 \mu \mathrm{M}$ to determine $\mathrm{K}_{\mathrm{d}}$.

F. Physical property assays: $\operatorname{LogD}$ and solubility was determined by a commercial service (WuXi, Hong Kong). For LogD, compound in $10 \mathrm{mM}$ DMSO was added to $100 \mathrm{mM}$ phosphate buffer (PB) (pH 7.4) saturated 1-octanol or 1-octanol saturated $100 \mathrm{mM}$ phosphate buffer at a final concentration of $66.7 \mu \mathrm{M}$. The tubes were vigorously shook for 2 minutes then shook for $1 \mathrm{~h}$ at 800 RPM at RT. Samples were centrifuged at 4000 rpm@ \&T for 5 minutes and aliquots of each layer made. Samples were diluted and detected by LCMS ( $0.1 \%$ formic acid in water $(\mathrm{A})$ or acetonitrile $(\mathrm{B}))$ and $\mathrm{Log} \mathrm{D}$ was calculated using the following equation:

$\log D_{\text {octanol } / \text { buffer }}=\log \left(\frac{\text { Mean Octanol Layer Peak Area Ratio } * \text { Octanol Layer Dilution Factor }}{\text { Mean Buffer Layer Peak Area Ratio } * \text { Buffer Layer Dilution Factor }}\right.$

Solubility was tested in 50mM PB (pH 7.4) and ADC medium by adding compound in DMSO and 50mM PB to whatman miniprep vials (GE Healthcare) at $200 \mu \mathrm{M}$ final concentration and vortexed for two minutes. Samples were shook for 24h@800 RPM and centrifuged at 4000 rpm for 20 minutes. Filtrate was injected onto HPLC (Mobile Phase A: 0.1\%TFA+2mM NH4OAc in water/ACN(v:v;95:5), B: 0.1\% TFA+2mM $\mathrm{NH} 4 \mathrm{OAc}$ in water/ACN(v:v;5:95)) with a standard curve to calculate concentration. 
G. Bacterial assays: The initial evaluation of 1 and select novel aminopyrimidines for activity against $M$. tuberculosis was performed using an auxotrophic strain of $\mathrm{H} 37 \mathrm{rv}$ in our laboratory following our previously published procedures. ${ }^{1}$ A full panel of assays was conducted using an attenuated Mtb strain, H37Ra (ATCC 25177), by a commercial service (WuXi, Hong Kong). The MIC determination of slow growing Mycobacteria is performed using the Alamar blue based assay ${ }^{17}$. Briefly, Mycobacteria strain is inoculated into $7 \mathrm{H} 9$ broth medium supplemented with $0.2 \%$ glycerol (vol./vol.), 10\% ADC enrichment and $0.05 \%$ Tween- 80 . The culture is grown at $37^{\circ} \mathrm{C}$ for 3-4 weeks until reaching OD550nm of $0.4-0.5$. The culture is washed twice in the cultivation medium. The resuspended suspension is aliquoted and stored at $-80^{\circ} \mathrm{C}$ for a maximum of six months.

On the day of experiment, the frozen strain stock from $-80^{\circ} \mathrm{C}$ is subjected to the dilution in $7 \mathrm{H} 9$ broth / ADC. $100 \mu \mathrm{l}$ the inoculum $(\sim 5 \mathrm{x} 104 \mathrm{CFU} / \mathrm{ml})$ is dispensed into the assay plate prefilled with 10 -point 2 -fold serial compound dilutions. The resulting assay plate is incubated at $37^{\circ} \mathrm{C},>80 \%$ humidity for 11 days. On the 11 st day, $12.5 \mu \mathrm{l} 7 \mathrm{H} 9$ medium supplemented with $20 \%$ tween- 80 and $20 \mu \mathrm{l}$ Alamar blue are added into the assay plate. The plate is continued to incubate at $37^{\circ} \mathrm{C}$ for $24 \mathrm{~h}$ prior to MIC inspection visually or fluorometrically.

The MIC is defined as the lowest drug concentration that prevents the color change from blue to pink. Alternatively, the fluorescence of each well is measured with excitation at $530 \mathrm{~nm}$ and emission at $590 \mathrm{~nm}$. Percent inhibition is defined as 1 - (test well FU/mean FU of bacteria only wells) x 100\%. The lowest drug concentration effecting an inhibition of $>=90 \%$ is defined as the MIC.

H. Cellular toxicity testing: Cytotoxicity testing was performed by a commercial service (WuXi, Hong Kong) with the THP-1 human macrophage cell line. Briefly, 3000 5000 cells, in 25 ul medium are seeded into the black 384-well plates (Greiner CELLSTAR® 384 well plates, 781091). The compounds are reconstituted into DMSO to $10 \mathrm{mM}$. Two-fold, 8-point serial compound dilutions starting at $50 \mu \mathrm{M}$ final concentration are added to the cell plates by Echo liquid transfer platform or manually, each in triplicates. DMSO and medium-only controls are included. The plates are incubated at $37^{\circ} \mathrm{C}, 5 \% \mathrm{CO}_{2}$ for $72 \mathrm{~h}$. At the endpoint, $25 \mu \mathrm{l}$ CTG are added to each well. Luminescence is measured using an Envision2104 Microplate Reader (PerkinElmer). The data (CC50) is analyzed with log (inhibitor) vs. normalized response -- Variable slope in GraphPad Prism.

I. Zebrafish toxicity testing: All experiments on live animals were approved by the University of WisconsinMadison School of Medicine and Public Health Institutional Animal Care and Use Committee (IACUC) and the William S. Middleton Memorial Veterans Hospital IACUC. All experiments were performed in accordance with all national and local guidelines and regulations. Compounds were evaluated for toxicity in zebrafish embryos as follows: Zebrafish were received from the breeding facility two days post fertilization (dpf) and dechorionated. Upon dechorionation, fish were transferred to fresh E3 zebrafish solution. Drugs were plated at $1.25 \mathrm{x}$ concentration to deliver 5,25 , or $50 \mu \mathrm{M}$ final concentration in E3. Each drug concentration was repeated in nine wells for a total of 27 wells per drug per trial. Zebrafish were transferred with a micropipette using large orifice tips standardized at $20 \mu \mathrm{L}$ per well to give the final concentrations of drugs with fish at 1x. The total volume of fluid is $100 \mu \mathrm{L}$ in each well. Outermost wells were filled with DI water to limit evaporation in test wells. Embryos were incubated at $28.0^{\circ} \mathrm{C}$ for five days. Plates were observed every 24 hours and presence of a regular heartbeat was considered the threshold for survival. Fish alive at the completion of the experiment were euthanized by placing fish in a bath of E3: bleach at a 5:1 ratio. The bath was then incubated at room temperature for five minutes before the solution was discarded per our animal use protocol. 


\section{Supplemental Figure 1}

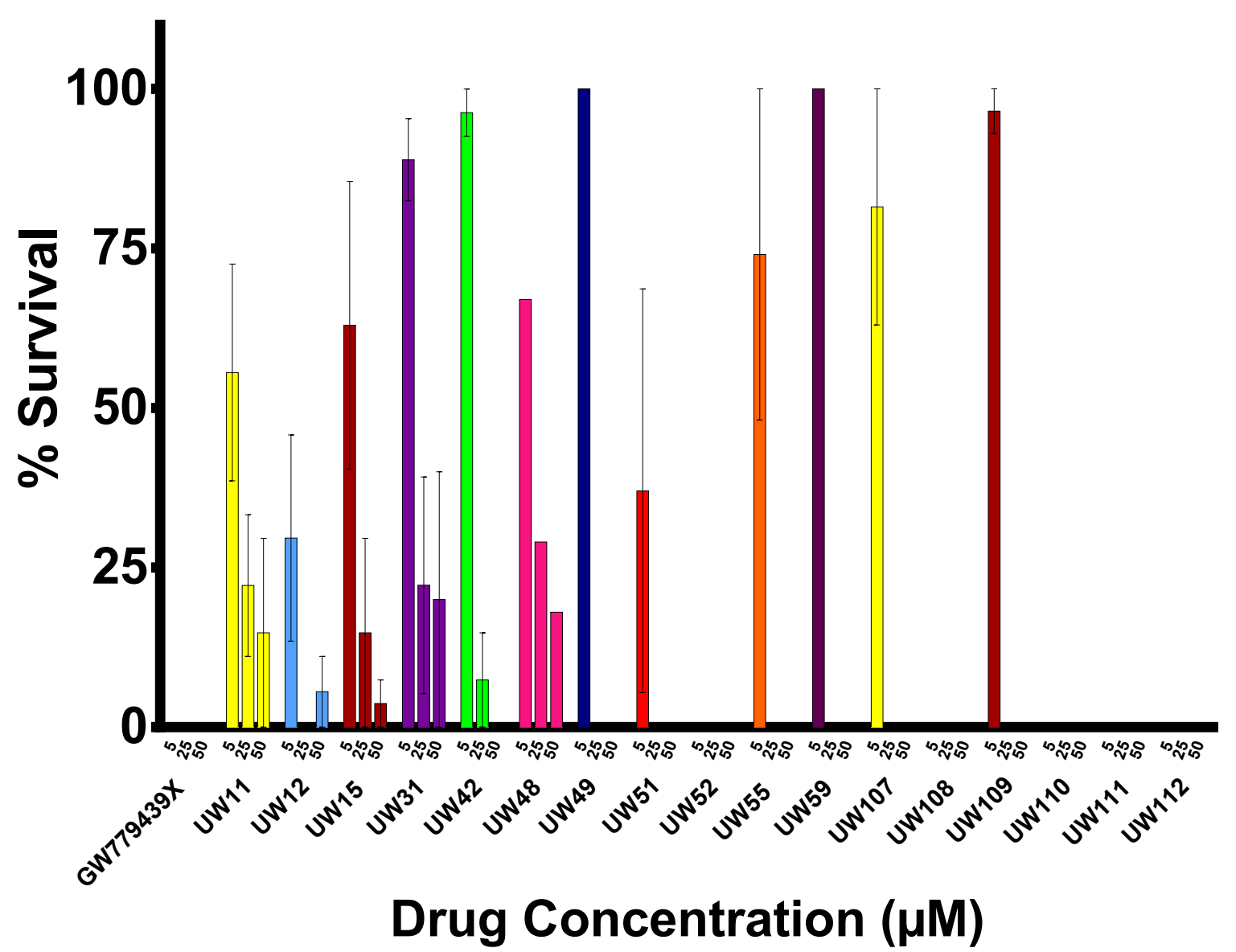

Figure S1. Zebrafish show a dose response for PknB inhibitor toxicity. Zebrafish were tested at three concentrations of novel $\mathrm{PknB}$ inhibitor and 12/18 were much less toxic than 1 , with 5 inhibitors showing some survival up to $50 \mu \mathrm{M}$.

\section{Supplemental References}

1. Wlodarchak, N.; Teachout, N.; Beczkiewicz, J.; Procknow, R.; Schaenzer, A. J.; Satyshur, K.; Pavelka, M.; Zuercher, W.; Drewry, D.; Sauer, J. D.; Striker, R., In Silico Screen and Structural Analysis Identifies Bacterial Kinase Inhibitors which Act with beta-Lactams To Inhibit Mycobacterial Growth. Mol Pharm 2018, 15 (11), 5410-5426.

2. Wlodarchak, N.; Guo, F.; Satyshur, K. A.; Jiang, L.; Jeffrey, P. D.; Sun, T.; Stanevich, V.; Mumby, M. C.; Xing, Y., Structure of the Ca2+-dependent PP2A heterotrimer and insights into Cdc6 dephosphorylation. Cell Res 2013, 23 (7), 931-46.

3. Zhang, H.; Ericksen, S. S.; Lee, C. P.; Ananiev, G. E.; Wlodarchak, N.; Yu, P.; Mitchell, J. C.; Gitter, A.; Wright, S. J.; Hoffmann, F. M.; Wildman, S. A.; Newton, M. A., Predicting kinase inhibitors using bioactivity matrix derived informer sets. PLoS Comput Biol 2019, 15 (8), e1006813.

4. Schaenzer, A. J.; Wlodarchak, N.; Drewry, D. H.; Zuercher, W. J.; Rose, W. E.; Ferrer, C. A.; Sauer, J. D.; Striker, R., GW779439X and Its Pyrazolopyridazine Derivatives Inhibit the Serine/Threonine Kinase Stk1 and Act As Antibiotic Adjuvants against beta-Lactam-Resistant Staphylococcus aureus. ACS Infect Dis 2018, 4 (10), 1508-1518. 
5. Young, T. A.; Delagoutte, B.; Endrizzi, J. A.; Falick, A. M.; Alber, T., Structure of Mycobacterium tuberculosis PknB supports a universal activation mechanism for Ser/Thr protein kinases. Nat Struct Biol 2003, $10(3), 168-74$.

6. Wang, T.; Bemis, G.; Hanzelka, B.; Zuccola, H.; Wynn, M.; Moody, C. S.; Green, J.; Locher, C.; Liu, A.; Gao, H.; Xu, Y.; Wang, S.; Wang, J.; Bennani, Y. L.; Thomson, J. A.; Muh, U., Mtb PKNA/PKNB Dual Inhibition Provides Selectivity Advantages for Inhibitor Design To Minimize Host Kinase Interactions. ACS Med Chem Lett 2017, 8 (12), 1224-1229.

7. Gay, L. M.; Ng, H. L.; Alber, T., A conserved dimer and global conformational changes in the structure of apo-PknE Ser/Thr protein kinase from Mycobacterium tuberculosis. J Mol Biol 2006, 360 (2), 409-20.

8. Scherr, N.; Honnappa, S.; Kunz, G.; Mueller, P.; Jayachandran, R.; Winkler, F.; Pieters, J.; Steinmetz, M. O., Structural basis for the specific inhibition of protein kinase G, a virulence factor of Mycobacterium tuberculosis. Proc Natl Acad Sci U S A 2007, 104 (29), 12151-6.

9. Y Yan, Q.; Jiang, D.; Qian, L.; Zhang, Q.; Zhang, W.; Zhou, W.; Mi, K.; Guddat, L.; Yang, H.; Rao, Z., Structural Insight into the Activation of PknI Kinase from M. tuberculosis via Dimerization of the Extracellular Sensor Domain. Structure 2017, 25 (8), 1286-1294.e4.

10. Jeffrey, P.D.; Russo, A.A.; Polyak, K.; Gibbs, E.; Hurwitz, J.; Massagué, J.; Pavletich, N.P.; Mechanism of CDK activation revealed by the structure of a cyclinA-CDK2 complex. Nature 1995, 376 (6538).

11. Takaki, T.; Echalier, A.; Brown, N.R.; Hunt, T.; Endicott, J.A.; Noble, M.E.; The structure of CDK4/cyclin D3 has implications for models of CDK activation. Proceedings of the National Academy of Sciences of the United States of America 2009, 106 (11).

12. Yang, J.; Yan, R.; Roy, A.; Xu, D.; Poisson, J.; Zhang, Y., The I-TASSER Suite: protein structure and function prediction. Nat Methods 2015, 12 (1), 7-8.

13. Boyer, S. J.; Guo, X.; Wu, D.; Wu, F. Pyridyl ureas as mineralocorticoid receptor antagonists. 201205-18, 2012.

14. Briner, K.; Camp, A. M.; Cornell, A.; Mazanetz, M. P.; Rothhaar, R. R.; Victor, F.; Williams, A. C.; Zhang, D.; Company, E. L. A. 6-N-linked heterocycle-substituted 2,3,4,5-tetrahydro-1H-benzo[d]azepines as 5-HT2C receptor agonists. 2007-03-08, 2007.

15. S, Z.; J, W.; L, W.; C, S.; K, C.; J, Z., Enaminones as Synthons for a Directed C-H Functionalization: Rh(III) -Catalyzed Synthesis of Naphthalenes. Angewandte Chemie (International ed. in English) 2016, 55 (32).

16. James Rodgers, S. S., Thomas Maduskuie, Haisheng Wang, Nikoo Falahatpisheh, Maria Rafalski, Argyrios Arvanitis, Louis Storace, Ravi Jalluri, Jordan Fridman, Krishna Vaddi Heteroaryl Substituted Pyrrolo[2,3-b]Pyridines and Pyrrolo[2,3-b] Pyrimidines as Janus Kinase Inhibitors. 6-14-2007, 2007.

17. Collins, L.; Franzblau, S. G., Microplate alamar blue assay versus BACTEC 460 system for highthroughput screening of compounds against Mycobacterium tuberculosis and Mycobacterium avium. Antimicrob Agents Chemother 1997, 41 (5), 1004-9. 